\title{
SIMULAÇÃO DAS CONDIÇÕES DE UTILIZAÇÃO DO TUBO DE PVC COM DIFERENTES PLASTIFICANTES EM UM PROCESSO DINÂMICO DE HEMODIÁLISE
}

\author{
Aline Celestino ${ }^{1}$, Écio Molinari2 ${ }^{\mathrm{i}}$, Palova Blazer ${ }^{3}$, Marcia Adriana Tomaz Duarte $^{4}$ \\ ${ }^{1}$ Universidade Sociedade Educacional Santa Catarina, Bacharelado em Engenharia Química \\ 2 Universidade Sociedade Educacional Santa Catarina, Mestrado em Engenharia Mecânica \\ ${ }^{3}$ Universidade Sociedade Educacional Santa Catarina, Mestrado em Engenharia Mecânica \\ ${ }^{4}$ Universidade Sociedade Educacional Santa Catarina, Mestrado em Engenharia Mecânica \\ E-mail para contato: alinne.celestino@hotmail.com
}

\begin{abstract}
RESUMO - O poli(cloreto de vinila) (PVC) é um dos materiais poliméricos com mais consumo atualmente. Apresenta uma grande importância na sociedade sendo aplicado em diversas área. Para obtenção de PVC flexível é necessário a utilização de plastificantes. Entre os plasificante mais utilizado no PVC destaca-se os plastificantes à base ftalatos, como o dioctil-ftalato (DOP) que vem sendo objeto de estudo por seu potencial cancerigino, entre outros efeitos adversos na saúde humana. Sendo assim, este trabalho tem como objetivo simular dinamicamente os tubos obtidos por compostos de PVC plastificado com DOP e PCL-T em um processo de hemodiálise. Foi realizada a simulação dinâmica dos tubos plastificados em um equipamento de hemodiálise. Após a simulação os tubos foram analisados por calorimetria exploratória diferencia (DSC) e termogravimetria (TG). Os ensaios de DSC sugerem uma migração dos plastificantes após as sessões de hemodiálise. As análises de TG evidenciam maior estabilidade térmica para os tubos plastificados com PCL-T comparado ao DOP. Embora houvesse migração dos dois plastificantes após processo de hemodiálise, a utilização do PCL-T não é nociva, pois este material é considerado compatível com o organismo, e expelido com facilidade do meio, não trazem riscos a saúde de pacientes em processos de hemodiálise.
\end{abstract}

\section{INTRODUÇÃO}

Os materiais plásticos têm extrema importância na sociedade moderna, sendo comumente encontrado no dia a dia das pessoas, entre eles destaca-se o poli(cloreto de vinila) (PVC), pelo sua utilização em diversas áreas. O PVC representa mais de $30 \%$ do material utilizado em hospitais europeus ${ }^{(1)}$,como por exemplo: bolsas de sangue, bolsas de soro, cateteres cardiovasculares, tubos endotraqueais, etc.

Para a obtenção de certas características como flexibilidade, utilizam-se plastificantes à base de ftalatos adicionado ao PVC. O mais comumente utilizado é o dioctil ftalato (DOP), que apresenta vantagens econômicas quando comparado com outros plastificantes, além de alta pureza $^{(2)}$. Entretanto, este plastificante em específico vem se tornando foco de pesquisa, pois podem migrar para a superfície do material polimérico em algumas condições de temperatura ou em contato com outras substâncias ${ }^{(3)}$. 
Muitas pesquisas relatam que a possível interação do DOP com o organismo animal ou humano pode causar severos problemas, como por exemplo, disfunção e mau desenvolvimento do aparelho reprodutivo masculino e até um possível risco cancerígeno ${ }^{(4)}$. Estudos com animais silvestres em laboratórios constataram que estes ftalatos podem causar não apenas danos à saúde reprodutiva, mas também abortos, defeitos congênitos, contagem anormal de espermas, danos testiculares e redução da fertilidade, além de câncer de fígado e rins $^{(5)}$. Em 2003, Gangi em seus estudos confirmou a presença significativa de DOP no sangue de recém-nascidos em um hospital na Itália ${ }^{(6)}$.

Estudos feitos em meninas de 6 aos 8 anos durante 4 anos concluiram que as meninas expostas aos ftalatos por longos períodos tiveram o início da puberdade tardiamente ${ }^{(7)}$. Em 2006, Rusyn veio a comprovar que o DOP contribui para a formação adenomas e carcinomas com resultados baseado em testes com roedores ${ }^{(8)}$. A preocupação se estende a todos os pacientes que são submetidos a longos tratamentos médicos que podem ser expostos a esses equipamentos como internações e o caso mais clássico, pacientes renais, que em uma única sessão com duração de quatro horas podem receber até $150 \mathrm{mg}$ de DOP, sendo este acumulativo no organismo e podendo causar danos à saúde ${ }^{(9,10)}$.

Considerando todos os fatos mencionados, vários estudos vêm sendo realizados com o objetivo de analisar a substituição do plastificante DOP, por um plastificante biorreabsorvivel, como o poli(caprolactona triol) (PCL-T) ${ }^{(11)}$ em matrizes poliméricas de PVC.

Sendo assim, este trabalho simulou dinamicamente os tubos obtidos por compostos de PVC plastificado com DOP e PCL-T em um processo de hemodiálise. Foram analisadas as propriedades físico-químicas, mecânicas e morfológicas destes tubos extrudados, visando uma alternativa não nociva à saúde humana.

\section{Materias e Metódos}

Para a realização da simulação dinâmica de um processo de hemodiálise utilizou-se os tubos de PVC/PCL-T e PVC/DOP extrudados adquiridos da UNISOCIESC proveniente do trabalho de conclusão de curso de Cardoso (2010). Para o procedimento de hemodiálise este estudo teve o apoio do Hospital Hans Schmidt juntamente com a Pró-Rim que cederam os equipamentos para esta pesquisa. Para simular a hemodiálise utilizou-se solução Tampão fosfato com pH em torno de 7.4, Bigbags de bicarbonato de Sódio USP (700 mg), um galão de solução ácida (cloreto de sódio, cloreto de potásio e associações 1:44 CPHD 23/44) framarim de dez litros, sendo o mesmo utilizado em várias sessões dependendo da disponibilidade no hospital.

Figura 1 - Simulação dinâmica em uma Máquina de Hemodiálise

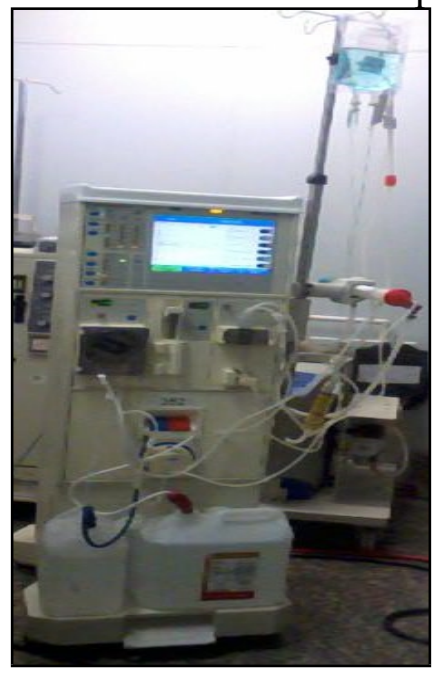




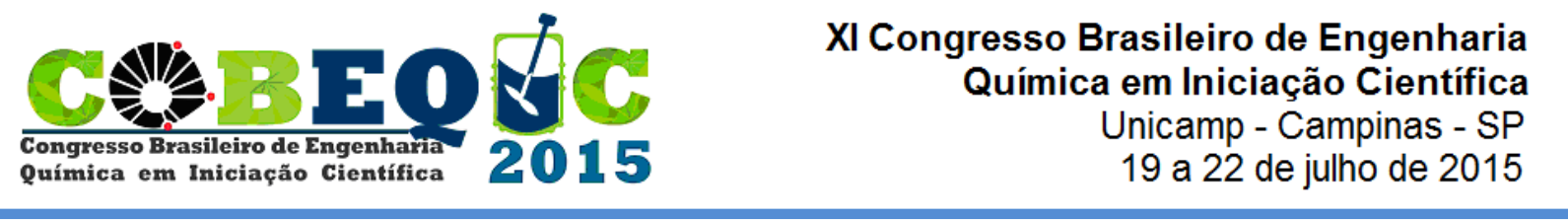

\subsection{Simulação dinâmica}

Para a realização da simulação dinâmica foi utilizada uma máquina de hemodiálise da marca Frenensius. Cada linha (PVC/DOP e PVC/PCL-T) foram submetidas a um processo de hemodiálise com duas horas de duração, passando por toda a preparação e desinfecção dos fios em cada sessão. As linhas foram reutilizadas 10 vezes no intuito de simular o procedimento atual. Foi escolhida a linha da saída da máquina até a dializadora e após a dializadora. Para simular o máximo possível as condições reais de um paciente em hemodiálise utilizaram-se a pressão constantes de trezentos mililitros por minuto $(\mathrm{ml} / \mathrm{m})$ e para a condutividade entre treze e quatorze $\mathrm{S} / \mathrm{m}$.

\subsection{Desinfecção das Linhas}

A desinfecção dos fios após cada hemodiálise é feita com o ácido peracético (proxitane), em um período de 24 horas. A retirada desse ácido do tubo é realizada na própria máquina de hemodiálise em funcionamento com soro fisiológico. Para verificar a total ausência do ácido perácetico, retira-se uma amostra em um recipiente que contém três gotas do reagente iodeto de potássio, se não escurecer a solução, inicia-se o processo de hemodiálise.

Figura 2. Capilar a ser desenfectado a cada sessão.

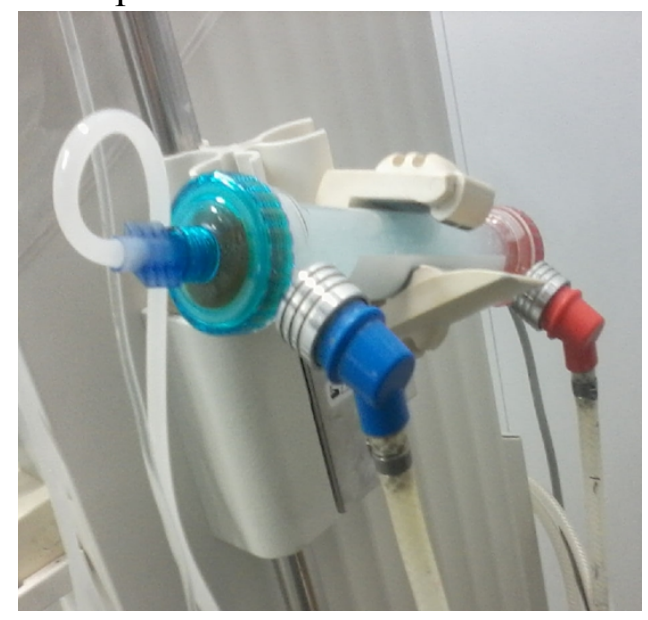

Assim após 10 sessões de 2 horas para cada fio com ambos os plastificantes, totalizando 20 sessões. Logo foram realizados ensaios tanto nos tubos, como nas soluções após a diálise, no intuito de verificar possível migração dos plastificantes PCL-T e DOP.

\subsection{Caracterização dos tubos de PVC plastificados}




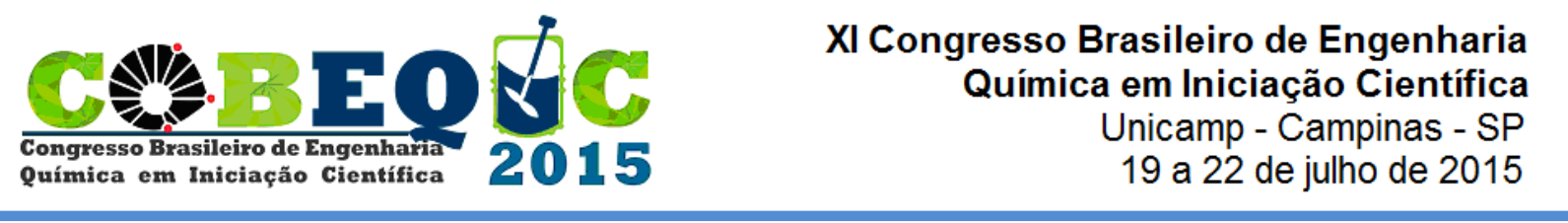

A seguir serão demonstradas as metodologias empregadas para a realização da caracterização dos tubos de PVC/PCL-T e PVC/DOP extrudados.

\subsection{Análise Termogravimétrica (TG)}

A análise termogravimétrica (TG) foi utilizada para determinar a estabilidade térmica dos tubos extrudados, nas formulações PVC/PCL-T e PVC/DOP.

O equipamento utilizado para a realização deste ensaio foi da TA Instruments modelo Q20, no Laboratório de Calorimetria Exploratória Diferencial, na SOCIESC. A taxa de aquecimento empregada foi de $10^{\circ} \mathrm{C} / \mathrm{min}$ em atmosfera de nitrogênio com temperatura de 25 a $700^{\circ} \mathrm{C}$.

\subsection{Análise de Calorimetria Exploratória Diferencial (DSC)}

A análise por Calorimetria Exploratória Diferencial (DSC) foi realizada para determinar a temperatura de transição vítrea $(\mathrm{Tg})$, a temperatura de cristalização ( $\mathrm{Tc}$ ) e a entalpia de cristalização $(\Delta \mathrm{Hc})$ das matérias-primas empregadas (resina de PVC, PCL-T e DOP) e dos tubos extrudados. O equipamento utilizado foi da TA Instruments modelo Q50, no Laboratório de Calorimetria Diferencial Exploratório, na SOCIESC.

Amostras pesando aproximadamente entre 7 e $10 \mathrm{mg}$ foram seladas em panelas de alumínio e aquecidas, em atmosfera inerte de nitrogênio, de $25^{\circ} \mathrm{C}$ a $200^{\circ} \mathrm{C}$ com uma taxa de aquecimento de $10^{\circ} \mathrm{C} . \min -1$ (primeiro aquecimento), e mantidas nesta temperatura por 5 minutos. $\mathrm{Na}$ sequência, elas foram resfriadas com taxa de $10^{\circ} \mathrm{C}$.min- 1 de $200^{\circ} \mathrm{C} \mathrm{a}-100^{\circ} \mathrm{C}$, e mantidas nesta temperatura por 5 minutos. Um segundo aquecimento foi realizado no intervalo de temperatura de $-100^{\circ} \mathrm{C}$ a $200^{\circ} \mathrm{C}$ com uma taxa de aquecimento de $10^{\circ} \mathrm{C}$.min- 1 .

Para as análises do PVC puro e da PCL-T pura alguns parâmetros foram modificados, para o PVC puro aqueceu-se a amostra até $200^{\circ} \mathrm{C}$ com uma taxa de aquecimento de $10^{\circ} \mathrm{C} \cdot \mathrm{min}-1 \mathrm{com}$ posterior resfriamento até $25^{\circ} \mathrm{C}$, seguido de uma isoterma de 5 minutos, e finalmente aquecido até $200^{\circ} \mathrm{C}$ com uma taxa de aquecimento de $10^{\circ} \mathrm{C}$.min-1, e para a PCL-T pura, a segunda corrida teve início em $-75^{\circ} \mathrm{C}$, com posterior aquecimento até $200^{\circ} \mathrm{C}$. Os demais parâmetros foram os mesmos descritos anteriormente.

\section{Resultados}

Através das curvas de DSC mostrado na Figura 3 e Tabela 1, pode-se observar um deslocamento da Tg do PVC/DOP sem hemodiálise comparado com o tubo após 10 seções de hemodiálise, as temperaturas passaram de $58^{\circ} \mathrm{C}$ para $61^{\circ} \mathrm{C}$, uma variação de $3^{\circ} \mathrm{C}$. $\mathrm{O}$ tubo PVC/PCL-T apresentou um comportamento semelhante ao PVC/DOP após as 10 sessões de hemodiálise aumentando a Tg de 60 para $63{ }^{\circ} \mathrm{C}$. Ambos os materiais sugeriram migração do composto do tubo para o liquido utilizado no processo dinâmico de hemodiálise. 
Tabela 1: Resultados obtidos nas analises de DSC e TG dos tubos de PVC plastificados com DOP e PCL-T antes e após processo de simulação de hemodiálise.

\begin{tabular}{l|l|l|l|l}
\hline & DSC & TG & \multicolumn{2}{l}{} \\
\hline Amostra & Tg $(\mathrm{oC})$ & Tg $(\mathrm{oC})$ & TG $(\mathrm{oC})-$ inicio & Residuo $(\%)$ \\
\hline PVC* & 85 & - & - & - \\
\hline PVC/PCL-T s/h & 60 & - & 235 & 35 \\
\hline PVC/DOP s/h & 58 & - & 180 & 22 \\
\hline PVC/PCL-T 10 h & 63 & - & 239 & 13 \\
\hline PVC/DOP 10 h & 61 & 82 & 167 & 22 \\
\hline
\end{tabular}

Figura 3. Resultados obtidos por TG dos tubos de PVC plastificados com DOP com e sem processo de hemodiálise transpostos com os resultados obtidos da TG de PVC com PCL-T com e sem processo de hemodiálise.

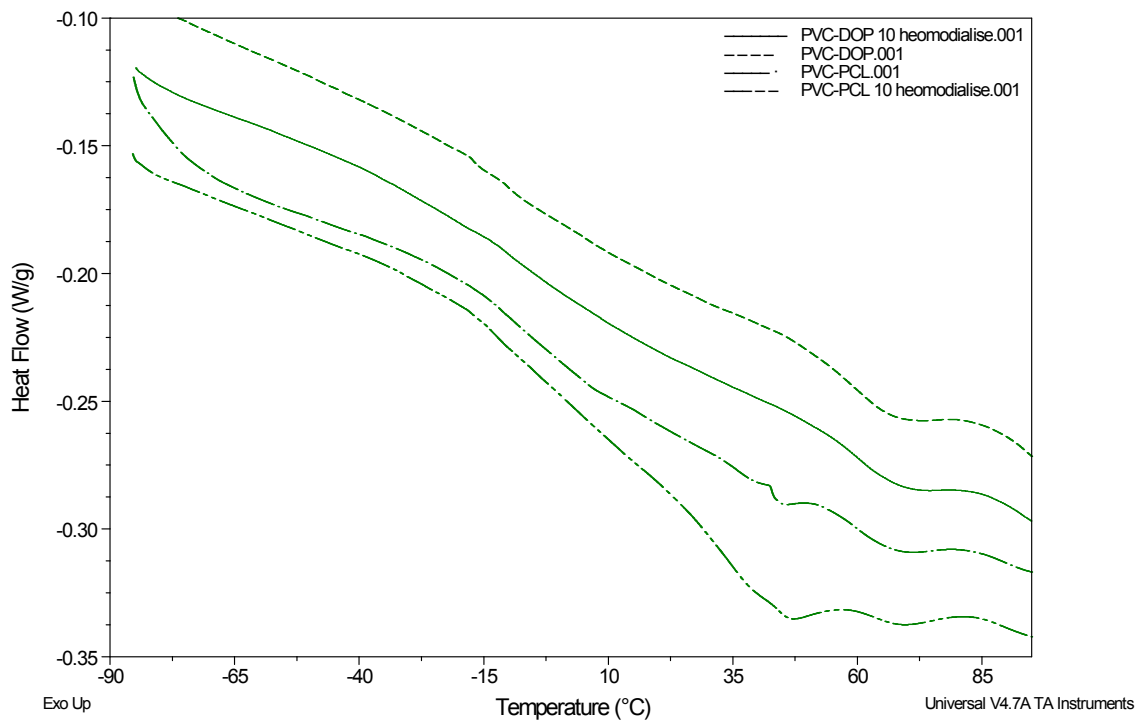

A Tabela 1 apresenta os resultados obtidos no ensaio de TG dos tubos de PVC plastificado com DOP e PCL-T com e sem o processo de hemodiálise.

Ao analisar as curvas de termogravimetria do PVC/DOP sem hemodiálise e com 10 seções de hemodiálise, nota-se a diminuição da temperatura de $\mathrm{TG}$ de $180{ }^{\circ} \mathrm{C}$ para $167{ }^{\circ} \mathrm{C}$, uma diferença de $13{ }^{\circ} \mathrm{C}$. Reduzindo em $7 \%$ a temperatura de inicio de degradação do composto de PVC apos realizado a hemodiálise. Constata-se que a massa degradada do composto do PVC com e sem hemodiálise é a mesma.

Com o composto de PVC com PCL-T constata-se que a temperatura de inicio de degradação com e sem hemodiálise não possuem diferenças significativas. Quanto à perda de massa destes compostos, constata-se que ocorre maior perda de massa após a hemodiálise. Mas os valores encontrados vão de acordo com a literatura (CARDOSO, 2011).

Analisando os compostos de PVC com DOP e com PCL, constata-se que as formulações com PCL-T apresentam maior estabilidade térmica que os compostos com DOP. Isto indica que a mistura do PVC e PCL-T podem interagir melhor entre as macromoléculas que o PVC com DOP. 


\section{Conclusão}

Constatou-se por análise termogravimétrica que os compostos de PVC/DOP são mais instáveis termicamente quando comparado com os compostos de PVC/PCL tanto com e sem o processo de hemodiálise. Os compostos plastificados com DOP após a hemodiálise apresentaram menor estabilidade térmica quando comparado com o PVC plastificado com DOP sem hemodiálise, indicando possíveis alterações estruturais dos compostos na hemodiálise e nos envolvidos do processo.

Compostos com PVC/DOP após processo de hemodiálise reduz o início da temperatura de degradação, isto pode sugerir uma reação com ácido peracético ou migração para o sistema de hemodiálise.

Apesar de constatado através da análise de DSC semelhança com os compostos de PVC entre os plastificantes, com PCL-T é considerado compatível com o organismo, e expelido com facilidade do meio, não trazem riscos a saude de pacientes em processos de hemodiálise.

\section{Referências}

1. PVC, Instituto do. 2011. Disponível em: http://www.institutodopvc.org. Acesso em: 05 de junho de 2012, $12 \mathrm{~h} 00 \mathrm{~min}$.

2. GRAY, T.J.; BUTTERWORTH, K.R.. Testicular atrophy produced by phthalate esters. Archives of Toxicology, Supplement, v. 4, p. 452-455, 1980.

3.BALZER, Palova Santos. Estudo Comparativo do Efeito Plastificante de Policaprolactonas diol e triol e Dioctil Ftalato em Poli (cloreto de vinila). Tese de Doutorado, Programa de PósGraduação em Ciências e Engenharia de Materiais - PGMAT. Universidade Federal de Santa Catarina, Florianópolis, 2009.

4. TANAKA, T. Reproductive and neurobehavioural toxicity study of bis (2-ethylhexyl) phthalate (DEHP) administred to mice in the diet. Food and Chemical Toxicology 40, p.14991506, 2002.

5. LATINI, C.D. et al. Environmental Health Perspective, 111, p.1783-1785, 2003.

6.GANGI. Joseph Di. Ftalatos em Produtos Médicos de PVC de 12 países. Greenpeace, EUA, 1999.

7. WOLFF, M.S, Phthalate Expousure and Pubertal Development in a Longitudinal Study in US Girls. Disponível em: http://humrep.oxfordjournals.org/content/29/7/1558.abstract. Acessado em 05 de janeiro de 2015 as 12:30 hrs.

8. RUSYN, Ivan et al. Modes of action and Species- Specific Effects if Di-(2ethylhexyl)Phthalate in the Liver, 2006, Vol. 36, No.5, Pages 459-479. 9. SUNNY, M.C.; RAMESH, P.; GEORGE, K.E.. Use of Polymeric Plasticizers in Polyvinyl Chloride to Reduce Conventional Plasticizer Migration for Critical Applications, J. Elast. and Plast. 36, p. 19-31, 2004.

10. HILL, A.S.; SHAW, B.R.; WU, A.H.B.. The clinical effects of plasticizers, antioxidants, and other contaminants in medical polyvinylchloride tubing during respiratory and nonrespiratory exposure, Clin. Chim. Act., 304, p. 1-8, 2001.

11. DUARTE, M.A.T., Influência da concentração de PCL-T em membranas de PLDLA. Estudo in vitro e in vivo, Campinas: Faculdade de Engenharia Mecânica, Universidade Estadual de Campinas, Tese Doutorado, 2009. 